\title{
LITERATURA, CULTURA E CONSTRUÇÃO DE IDENTIDADES: O VELHO E O NOVO, O CAMPO E A CIDADE EM MIA COUTO
}

\author{
LITERATURE, CULTURE AND THE \\ CONSTRUCTION OF IDENTITIES: OLD PEOPLE \\ AND NEW PEOPLE, THE COUNTRYSIDE AND \\ THE CITY IN MIA COUTO
}

\author{
Lourdes Ana Pereira Silva ${ }^{1}$ \\ Maria Auxiliadora Fontana Baseio ${ }^{2}$
}

\section{RESUMO}

Este trabalho tem por objetivo analisar as questões que envolvem a construção da cultura e da identidade a partir das inter-relações velho/novo, campo/cidade. O contexto mais amplo da problematização é a negociação que se estabelece na relação entre velho e cidade na literatura moçambicana e que elege por objeto de análise o conto do autor Mia Couto intitulado "A avó, a cidade e o semáforo". Metodologicamente, este trabalho é de natureza bibliográfica e tem por principais categorias de observação e análise a cidade e o velho em suas implicações com o conceito de identidade.

PALAVAS-CHAVE: Identidade; literatura; cidade.

\section{ABSTRACT}

This work aims to analyze the issues that involve the construction of identity based on the interrelations between old/new people and countryside/ city. The broader context of the problematization is the negotiation that is established in the relation between old people and city in the mozambican literature and it chooses by object of analysis the story of Mia Couto titled "A avó, a cidade e o semáforo". Methodologically, this work is of a bibliographical nature and has as its main categories of observation and analysis the city and the old people in its implications with the concept of identity.

KEYWORDS: Identity, literature; city. 


\section{INTRODUÇÃO}

Historicamente, o campo dos Estudos Culturais relaciona-se com a alteração no pensamento inglês do pós-guerra. A Escola de Birmingham partiu de uma concepção de cultura que está fortemente relacionada ao pensamento crítico. Para Raymond Williams (1992, p. 13), cultura é um sistema de significações em face do qual uma ordem social é comunicada, reproduzida, vivenciada e pensada. Sua compreensão parte do princípio de que cultura é um campo privilegiado, um espaço de compreensão crítica da sociedade, de questionamento sobre o papel da chamada alta cultura. Nessa perspectiva, a proposição de Williams é da cultura em comum, trata-se de uma concepção materialista cuja definição passa por entendimento histórico do modo de produção. O autor alerta para o aspecto interativo e comum da produção cultural, apostando nas trocas entre indivíduos de classes ou grupos sociais diversos, abarcando não apenas a herança cultural da humanidade, mas também os processos criativos da vida ordinária de pessoas comuns.

Richard Hoggart, outro expoente da Escola de Birmingham, destaca a tradição literária dos ingleses, decorrente de dois séculos de processos de urbanização, industrialização e democratização. Tais questões influenciaram diretamente a pesquisa literária de Hoggart, aproximando-a da experiência viva da literatura no âmbito da cultura erudita e também popular, ou seja, o método dos Estudos Culturais partiu da análise literária para a cultural (CEVASCO, 2003).

A mesma autora ressalta as questões de caráter metodológico contidas na fala de Hoggart, quando este afirma que "[...] a leitura crítica da poesia é uma disciplina árdua, poucos exercícios nos revelam mais nitidamente as limitações que sofremos em diferentes momentos" (CEVASCO, 2003, p. 34). Hoggart vai mais além ao afirmar que "a lição da grande poesia parece ser que, quando a compreendemos, na medida em que isso nos faz reorganizar a experiência, não precisamos de mais nada" (CEVASCO, 2003, p. 34).

A importância dos Estudos Culturais para os Estudos Literários é inegável na medida em que se coloca em relevo a urgência da interdisciplinaridade. Diante da miopia que vem nos acompanhando acerca das questões do humano no contexto cultural contemporâneo, compartilhamos com Morin (2012) a necessidade de enfrentar desafios culturais, sociológicos, cívicos, a fim de decifrar, por meio da reintegração dos saberes, essa tessitura conjuntiva, multirreferencial e complexa que se define como o mundo fenomênico.

A noção de interdisciplinaridade integra a gênese dos Estudos Culturais a partir do momento em que revela aportes de outros campos do conhecimento, como a Filosofia, a Psicanálise e a Psicologia, a Sociologia, a Antropologia e a Semiótica, ao contemplar determinados aspectos da vida social, a partir de uma cultura específica. Pós-modernidade, globalização, 
pós-colonianismo, hibridismo e multiculturalismo são temáticas frequentes Nesses estudos e respondem à problemática da relação da Literatura com a História, o que certamente contribui para analisarmos o contexto de produção de Mia Couto e do conto "A avó, a cidade e o semáforo".

Se tomarmos o direcionamento crítico dos Estudos Pós-coloniais para tratar das literaturas africanas de língua portuguesa e outras literaturas emergentes, empreenderemos reflexões sobre as práticas culturais e as relações de poder resultantes da ideologia colonial.

As afinidades entre os Estudos Culturais e os Pós-coloniais no tratamento das literaturas africanas de expressão lusófona possibilitam análises sobre o local e o global, buscando esquadrinhar as condições de produção e os contextos socioculturais em que se realizam essas literaturas emergentes. Nessa perspectiva, as imbricações entre Literatura e História mostram-se profícuas ao se tratar de Moçambique e de sua literatura, uma vez que às recentes lutas pela independência somam-se as questões relacionadas ao embate de culturas e à construção de identidades.

Nesse contexto, cumpre destacar que este artigo pretende analisar as questões que envolvem a construção de identidades no âmbito dos respectivos espaços culturais que se apresentam no conto. Considera-se, em um primeiro momento, a problematização da cidade como espaço de construção de identidades na perspectiva dos Estudos Culturais e, em um segundo momento, a cidade no contexto literário de Mia Couto. Do ponto de vista teórico, este trabalho beneficia-se, principalmente, das contribuições de Stuart Hall e Raymond Williams, bem como das contribuições de Pierre Bourdieu, Zygmunt Bauman, Manuel Castells. Consideram-se, ainda, os aportes latino-americanos de Jesús Martín-Barbeiro e Néstor García Canclini para discutir as questões relativas às identidades.

\section{A CIDADE COMO ESPAÇO DE CONSTRUÇÃO DE IDENTIDADE}

No livro As cidades invisíveis, Ítalo Calvino destaca como é possível "construir" diferentes cidades, quando, na verdade, trata-se de apenas uma só, conforme sejam considerados determinados aspectos. Desse modo, percebe-se que a cidade só existe como relação entre os diferentes grupos que interagem em um dado sistema de produção. Cada grupo, com seu modo de conceber, pode construir e reconstruir a cidade criativamente, a partir de elementos eleitos pela diversidade disponibilizada pela cultura de uma dada sociedade. Isto é, a cidade pode ser "construída" a partir da geografia, da geração, da profissão, do lazer, da política, da religião, da música e sempre haverá uma cidade a ser construída conforme sejam privilegiados aspectos específicos (SILVA, 2010).

Há que se considerar, ainda, que o espaço urbano não é apenas receptor, não é mero cenário de experiências, de interações e de encontros. As atividades humanas interagem com os espaços que elas produzem e, 
assim como as novas tecnologias e formas de produção e de vida, são constituintes dessa interação. O espaço da cidade estrutura as ações dos indivíduos e as interações em uma sociedade, onde os significados produzidos são aqueles da prática.

A noção deste conceito em Michel de Certeau (1998) significa vivência, isto é, um lugar só se torna espaço quando os indivíduos exercem suas práticas. Quando ocupado, o lugar é evocado e modificado, passando à condição do que Certeau denomina de "lugar praticado". Para o autor, só há identidade no espaço quando há práticas decorrentes dos indivíduos. Desse modo, a cidade pode ser considerada uma manifestação de modo de vida, do imprescindível viver em sociedade, um produto do indivíduo e da sua intervenção no seu habitat.

A noção de espaço para Castells (1999) assemelha-se à de Certeau (1998), na medida em que está diretamente relacionada às práticas sociais de tempo compartilhado:

Espaço é um produto material em relação a outros produtos materiais - inclusive as pessoas - as quais se envolvem em relações sociais [historicamente] determinadas que dão ao espaço uma forma, uma função e um sentido social (CASTELLS, 1999, p. 500).

Se tomarmos a cidade como discurso e texto, ou ainda, como cenário e espaço da construção e exercício dos símbolos identitários, é oportuno o pensamento de Hall ao afirmar que:

[...] a representação envolve produzir significação forjando elos entre três diferentes ordens das coisas: o que podemos geralmente chamar de o mundo das coisas, pessoas, eventos e experiências; o mundo conceptual, os conceitos mentais que levamos em nossa mente; e os signos, arranjados nas línguas que "significam" ou comunicam estes efeitos. (HALL, 1997, p. 61, tradução nossa)

Portanto, não seriam discursos neutros, uma vez que tenderiam a estabelecer determinada visão de mundo, que implica comportamentos e escolhas. Representar tem o caráter de anunciar, "pôr-se no lugar de", constituindo uma semelhança capaz de possibilitar identificação e reconhecimento entre representante e representado.

Bourdieu (2006), por sua vez, considera o poder simbólico como construtor da realidade cujas representações dependem profundamente do conhecimento e do reconhecimento, visto que "quem tem o poder de representar tem o poder de definir e determinar a identidade. É por isso que a representação ocupa um lugar tão central na teorização contemporânea sobre identidade" (SILVA, 2000, p. 91).

Ainda no que se refere à noção de espaço, na obra $O$ campo e a cidade: na história e na literatura, Raymond Williams (2011) resgata, em sua língua, a etimologia dos termos campo e cidade. Em inglês, o verbete coun- 
try pode significar país ou campo. Para Williams, há atitudes emocionais que se cristalizaram em torno do campo e da cidade. Muitas vezes, o campo é associado à vida natural, à paz e à virtude simples, enquanto a cidade é vista como o centro das realizações e é associada ao saber, às comunicações e à luz. Outras concepções associam o campo ao atraso, limitação e ignorância, e a cidade ao barulho e à ambição. Campo e cidade, para Williams, são realidades históricas em constante transformação, em si próprias e em suas inter-relações. Para o autor, há uma experiência social concreta do campo, da cidade e de muitas outras organizações sociais e físicas intermediárias. Apesar disso, ainda são muito latentes as imagens que opõem campo e cidade. O autor acredita em uma necessidade de se confrontar as representações de campo e cidade com as realidades históricas, uma vez que a oposição entre ambos, tal como é colocada nas obras literárias analisadas em sua pesquisa, é um reflexo da constituição capitalista mundial.

Para García Canclini (2005), o bairro, a cidade, a nação são cenários de identificação de produção e de reprodução cultural. Percebe-se, desse modo, que o conto do autor Mia Couto propicia reconhecimento local, uma vez que há uma dependência de definições centralizadas em níveis geográficos e culturais.

\section{A CIDADE NA LITERATURA DE MIA COUTO: O CONTO "A AVÓ, A CIDADE E O SEMÁFORO"}

A obra do escritor moçambicano entrelaça elementos culturais, históricos e estéticos. Como realidade própria, expressa uma visão de homem, de cultura, de sociedade, bem como uma posição diante de temas relevantes por meio dos quais se torna possível compreender "o espírito e a sociedade" de seu tempo, relembrando Antonio Candido (1997, p.34).

Em Estórias Abensonhadas, narra-se:

Toda estória se quer fingir verdade. Mas a palavra é um fumo, leve de mais para se prender na vigente realidade. Toda verdade aspira ser estória. Os factos sonham ser palavra, perfumes fugindo do mundo. Se verá neste caso que só na mentira do encantamento a verdade se casa à estória. (COUTO, 1998, p. 51)

Como prática simbólica, a literatura abre canais de percepção e de compreensão da realidade, alargando a capacidade crítica de olhar. Cumpre reconhecer fatores externos, sociais, vinculados ao contexto histórico, bem como fatores individuais, próprios da consciência criadora, não deixando de destacar o texto como realidade autônoma. Para relembrar as palavras de Antonio Candido:

Uma obra é uma realidade autônoma, cujo valor está na fórmula que obteve para plasmar elementos não-literários: impressões, paixões, idéias, fatos, acontecimentos, que são a matéria-prima do criador. A sua importância quase nunca 
é devida à circunstância de exprimir um aspecto da realidade, social ou individual, mas a maneira por que o faz. No limite, o elemento decisivo é o que permite compreendê-la e apreciá-la, mesmo que não soubéssemos onde, quando, por quem foi escrita. Esta autonomia depende, antes de tudo, da eloqüência do sentimento, penetração analítica, força de observação, disposição das palavras, seleção e invenção das imagens; do jogo e elementos expressivos, cuja síntese constitui a sua fisionomia, deixando longe os pontos de partida não-literários. (CANDIDO, 1997, p. 33)

Um escritor recria, em sua obra, elementos da realidade histórica a partir de imagens que habitam seu imaginário, traduzindo, afetiva e esteticamente, percepções, observações, aspirações, guiado por sua consciência de linguagem. Há uma consciência do fazer literário em Mia Couto, passível de observação pela forma de expressão da matéria literária. Ao analisarmos a obra do autor, descobrimos uma lógica tradutora da singularidade cultural moçambicana em que se revelam as relações entre o velho e o novo, evidenciadas na projeção dos espaços do campo e da cidade.

Para melhor compreender essas relações de sentido, vale relembrar alguns aspectos da história de Moçambique. Por servir de rota marítima milenar, esse território configura-se como espaço de encontro de pessoas e visões de mundo; culturalmente, revela-se um tecido compósito de saberes diversos e, portanto, um entre-lugar marcado por tensões identitárias. No século XIX, os desdobramentos do neocolonialismo alteram percepções e representações identitárias a partir da construção de uma nação imaginada na perspectiva do projeto político colonial. Nesse contexto, a tensão entre o moderno projeto nacional de caráter colonial e as reconstruções identitárias (ideológicas, étnicas, raciais, religiosas etc.) dele decorrentes suscita uma coexistência nada pacífica. A condição colonial define a identidade pela raça, as hierarquias são fundadas nessa condição de pertença.

No seio desse projeto de construção de uma identidade nacional nas bases do colonialismo, surgem os movimentos de resistência que levaram à formação da Frente de Libertação de Moçambique (FRELIMO), um partido único que vislumbrava a luta armada, sendo presidido por Samora Machel nos anos 1980.

A força das armas associada à força da lei e a imposição cultural de uma língua acabam por esvaziar imagens, cosmogonias, representações, sentidos de pertença. Esse colonialismo tardio a que se somaram as lutas nacionalistas em torno da independência e o socialismo de matriz marxista-leninista são eventos históricos importantes para a leitura da história e da literatura que emerge desse campo de tensões.

É fato que as marcas dos Estados coloniais foram decisivas para as sociedades africanas, entretanto há que se considerar, também, essas lutas endógenas de poder, se o desejo é ir além do binômio colonizador/coloni- 
zado, pois é nesse contexto que se desenvolve a dinâmica da construção das identidades. Se o projeto colonial rasurou as vozes da tradição, silenciando saberes e formas de conhecimento de mundo genuínos, o projeto político socialista de Samora Machel não fez muito diferente, ao entoar o lema: "Morra a tribo para que nasça a nação". Ambos os discursos, cada qual à sua maneira e segundo sua ideologia, preconizaram ideias de sobreposição da identidade político-ideológica nacional em detrimento dos elementos identitários singulares, como o regionalismo, o tribalismo, o tradicionalismo.

Nesse contexto, a imposição da língua portuguesa - do colonizador - foi fundamental, primeiramente para garantir a afirmação cultural do imaginário lusitano e sua força de dominação; em segundo lugar, para providenciar a comunicação entre os membros das várias etnias no encalço de uma unidade a fim de criar resistência ao projeto colonial e também para inserir Moçambique no contexto moderno internacional.

A literatura moçambicana, realizada por meio de palavras escritas, emerge nesse contexto de tensões, e Mia Couto consegue captar, nos subterrâneos desses projetos hegemônicos, as possibilidades de trocas culturais das diversas identidades e as traduz inventivamente na perspectiva da partilha. Avesso à visão essencialista, põe em relevo a complexidade dessas dinâmicas e a diversidade das matrizes culturais, enfatizando o caráter relacional dessas construções identitárias a partir dos espaços culturais em que se engendram, no conto analisado, o campo e a cidade.

Em Raiz de Orvalho e outros poemas, Mia Couto sugere:

Preciso ser um outro

Para ser eu mesmo[...]

Existo onde me desconheço

Aguardando pelo meu passado

Assinando a esperança do futuro

(COUTO, 1999, p. 13)

Como um pensador da identidade histórica e cultural de seu país, seu projeto estético e político desafia a narrativa unívoca, imprimindo-lhe o caráter plurivocal. No conto em análise, essa condição é apresentada a partir das figuras e dos lugares de enunciação: do velho, a princípio ancorado no campo, e do novo, representado pela cidade.

\section{Como explica o autor em Pensatempos}

Deixámos de escutar as vozes que são diferentes, os silêncios que são diversos. E deixámos de escutar não porque nos rodeasse o silêncio. Ficámos surdos pelo excesso de palavras, ficámos autistas pelo excesso de informação. A natureza converteu-se em retórica, num emblema, num anúncio de televisão. Falamos dela, não a vivemos. A natureza, ela própria, tem que voltar a nascer. (COUTO, 2005, p. 123)

O escritor moçambicano, em seu projeto estético, busca sensibilizar para a escuta das várias vozes capazes de "fazer a cidade", de interagir na sociedade. Além disso, cria um narrador que se reveste de contador, va- 
lorizando aspectos da tradição oral que tendem a se perder na sociedade da escrita. Do ponto de vista estético, ele literaliza recursos da tradição oral, construindo uma espécie de oralitura, em que a língua portuguesa é vista e empregada como um sistema aberto e pleno de afetividade. Ecoando a oralidade nas fissuras da letra, "o viajante de identidades", como se define em Pensatempos (COUTO, 2005, p. 59) opta por enredar tradição e modernidade, transformando suas criações estéticas em tessituras de contiguidade, em que se avizinham 'falescrita' ou 'oralitura' (BASEIO, 2007, p. 163).

Sabemos que oralidade implica condição daquilo que em nós se orienta diretamente para o outro. Por isso, a escuta tem caráter gregário, porque, ao falar, nós nos entregamos ao outro e, ao escutar, acolhemos o outro, abrindo-nos ao diferente, favorecendo a construção de laços comunitários, assim como observamos nas sociedades de tradição oral e marcadamente as que povoam o campo.

Amadou Hampâte Ba (apud MATOS, 2005. p.79) costumava dizer que "na África é contando histórias que se constrói a aldeia”. Walter Benjamin enfatiza a marca artesanal da narração nessas comunidades de tradição oral e que se diferenciam profundamente na sociedade da informação que ganha força e forma sobretudo nas cidades.

Mia Couto, neste conto, bem como no conjunto de sua obra, coloca em jogo o mundo moderno e impessoal da informação ancorado na cidade com o mundo sensível e afetivo dos laços familiares e do contato íntimo com a natureza. Esse antagonismo é bem marcado no início do texto, especialmente no que diz respeito à natureza das relações sociais, quando a avó Ndzima, diante da notícia de que o neto viajaria para a cidade para ganhar o prêmio de melhor professor rural, pergunta com suspeitas:

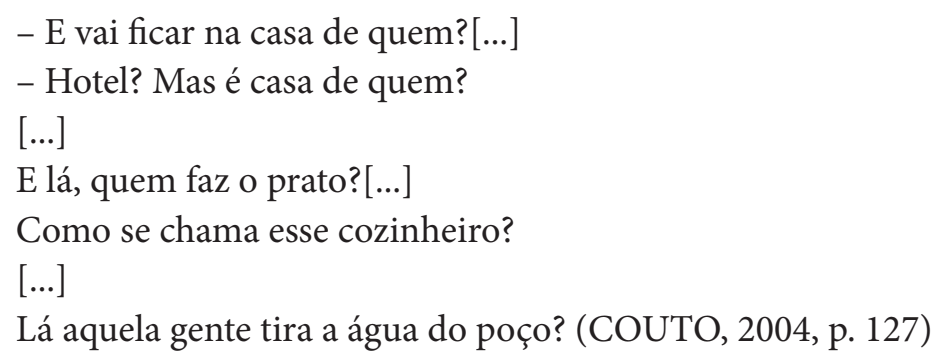

A passagem deixa claro o contraponto entre o grau de intimidade e de afetividade das relações no campo em relação à frieza, impessoalidade e anonimato das relações da cidade.

E, em primeira pessoa, recuperando a voz da experiência, acrescenta o narrador-personagem:

Ri, sem palavra, mas, para ela, não havia riso, nem motivo. Cozinhar é o mais privado e arriscado acto. No alimento se coloca ternura e ódio. Na panela se verte tempero e veneno. Quem assegurava a pureza da peneira e do pilão? Como eu podia deixar essa tarefa, tão íntima, ficar em mão tão anô- 
nima? Nem pensar, nunca tal se viu, sujeitar-se a um cozinhador de quem nem o rosto se conhece? (COUTO, 2004, p.128).

A oposição que se cria também com o uso dos advérbios aqui e lá, do outro lado, além da sugestão do nós (campo) em contraposição ao eles/ outros (cidade), reiteram essa observação, como se lê no trecho:

Que aquilo lá, tudo era de outro fazer. Mas ela não arredou coração. Não ter família, lá na cidade, era coisa que não lhe cabia. A pessoa viaja é para ser esperado, do outro lado a mão de gente que é nossa, com nome e história. (Couto, 2004, p.128).

A expressão “Que aquilo lá, tudo era de outro fazer” revela uma percepção de não pertencimento ao mundo de lá.

As diferenças culturais também ficam marcadas e se mostram antagônicas no conto quando o narrador compara a forma como se dorme na aldeia - despido - e o modo de dormir da cidade - vestido.

A surpresa da narrativa, marcada por um tom de humor irônico, é o fato de, mesmo resistindo à cultura asséptica da cidade, a velha resolver acompanhar o neto. E levar "a cangarra com galinhas vivas". Apesar de sofrer represálias da gerência do hotel, dá entrada com os animais e descobre que o cozinheiro era de sua terra - o que conota a movimentação campo/cidade com o processo de urbanização - e isso lhe trouxe mais confiança de se estabelecer na cidade ao encontrar um dos seus. E assim, a avó foi se aclimatando no novo espaço, de tal maneira que não desejou retornar ao campo.

É recorrente nas narrativas de Mia Couto essa síntese surpreendente, uma espécie de confirmação da dialética hegeliana, que se revela no dizer da velha:

- Vou ficar, meu neto.[...]

- Vai ficar sozinha?

- Lá, na aldeia, ainda estou mais sozinha.

(COUTO, 2004, p. 130).

Assim, o neto retorna para o campo, convivendo com a antiga cultura, e a avó compartilha sua sabedoria com a nova cultura na cidade. Nessa nova composição híbrida de identidades, revela-se o pressuposto do escritor que intenta colocar em diálogo o velho e o novo. Tais questões reforçam que as identidades não são unificadas, mas fragmentadas, fraturadas, que não são singulares, mas múltiplas e construídas ao longo de discursos, práticas e posições. Como afirma Hall, "as identidades estão sujeitas a uma historização radical, estando constantemente em processo de mudança e transformação" (HALL, 2000, p. 108).

Finalmente, o bilhete que ela dita para alguém escrever chega às mãos do neto convidando-o para visitá-la na cidade. No documento, contam as significativas palavras: "agora, neto, durmo aqui perto do semáfo- 
ro. Faz-me bem aquelas luzinhas, amarelas, vermelhas. Quando fecho os olhos até parece que escuto a fogueira, crepitando em nosso velho quintal..." (COUTO, 2004, p. 131).

A relação de equivalência simbólica que se estabelece entre as cores do semáforo e da fogueira - amarelo e vermelho - reverberam a confluência das duas culturas e das duas temporalidades. Assim se revela a importância dos elementos antigos da tradição em relação de contiguidade com os elementos novos da modernidade.

Nas sociedades tradicionais, a experiência é narrada em favor do coletivo (Erfahrung) e as contações de histórias ao redor do fogo retratam isso, valorizando a experiência compartilhada e não individual (Erlebnis = vivência). Nesse sentido, a memória é a fonte privilegiada, garantidora de que a experiência não cairá no esquecimento. Assim, justifica-se a importância dos velhos, guardiões dessa memória e transmissores das experiências - como a avó Ndzima -, em íntima relação com os novos, o neto, narrador-personagem da história.

Vale ressaltar que, na cultura moçambicana, devido ao culto à ancestralidade, a velhice é um período da existência humana a que todos aspiram, pois a crença na sobrevivência pós-morte valoriza os anciãos ponte entre vivos e mortos.

O velho, "guardião do tesouro espiritual da comunidade, a tradição” (BOSI, 1994, p. 82), ganha lugar de honra, e está sempre em relação com o novo, guardião do porvir.

Ensina Laura Cavalcanti Padilha:

[...] o novo e o velho, juntos e interativamente articulados, eis uma vez mais reatualizada, no corpo do novo discurso, a imagem fundadora. [...] Com essa troca a interação velho/ novo se torna, nas malhas do moderno tecido-texto, cada vez mais intensa e fecundante, com a tradição e a transformação recriando-se mutuamente. (PADILHA, 1995, p. 44)

Considerando as tensões que seu contexto de produção lhe confere, Mia Couto deixa clara sua compreensão de que a tradição, enraizada na terra, no campo, reclama, insistentemente, pela permanência, em face dos contínuos apelos da modernidade, do progresso e das demandas da cidade. Nesse contexto, Moçambique deve gestar um novo homem, que não deverá ser o velho, cristalizado na tradição, tampouco o novo, deslumbrado com a modernidade, mas uma síntese de ambos. Essa ideia é muito bem recriada pelo conto em análise.

A síntese desses dois espaços e tempos - campo/passado e cidade/ futuro - concretiza-se na figuração das duas personagens: a avó e o neto. $\mathrm{O}$ velho é signo da sabedoria, a voz da experiência contada em estórias, portador da voz das origens, da tradição oral, e não se coaduna com a cultura escrita, com o mundo dos livros, como se observa, por exemplo, em Um rio chamado tempo uma casa chamada terra, em que Mariano sai da Ilha, atra- 
vessa "a fronteira do mundo", vai para outra margem onde inicia a cidade, o mundo dos livros, que afasta as pessoas. "Os livros são um estrangeiro, para mim. Porque eu estudo na chuva. Ela é minha ensinadora” (COUTO, 2003, p. 149). Ou então: "o senhor lê o livro, eu leio o chão." (COUTO, 2005, p.155). É inegável que o livro, principal forma de comunicação da modernidade, é lugar privilegiado da escrita e considerado elemento de cisão do homem com a natureza. Entretanto, é por meio dele que o escritor moçambicano oferece a possibilidade de reconciliação do homem moçambicano com sua terra. Na voz do narrador, argumenta Mia Couto em A varanda do frangipani: "eu sei, estou enchendo de saliva sua escrita. Mas, no fim, o senhor vai entender isto que estou para aqui gargantear" (2003, p.29). O autor gestualiza o texto, griotiza a expressão narrativa, rememorando, no ato solitário da leitura, o ato solidário da narrativa da tradição oral.

Ao escolher o conto como gênero, Mia Couto faz reverberar o gesto vocal das narrativas da tradição, capaz de enlaçar os homens, na alma do novo texto escrito. Se gênero e forma constituem instrumental de expressão de mundividências, como afirma Massaud Moisés (1982, p. 266), a prosa narrativa em forma de conto é, para Mia Couto, sua principal arma de libertação.

Para ele, o conto assim se define:

O conto é feito com pinceladas. É um quadro sem moldura, o início inacabado de uma história que nunca termina. O conto não segue vidas inteiras. É uma iluminação súbita sobre essas vidas. Um instante, um relâmpago. O mais importante não é o que revela, mas o que sugere, fazendo nascer a curiosidade cúmplice de quem lê. No conto o que vale não é tanto o enredo mas o surpreender em flagrante a alma humana. No conto (como em qualquer gênero literário) o mais importante não é o seu conteúdo literário, mas a forma como ele nos comove e nos ensina a entender não através do raciocínio mas do sentimento. (COUTO, 2005, p. 46)

O conto "A avó, a cidade e o semáforo" traz uma súbita visão do que vive no imaginário do escritor, suas ideias, impressões, vivências e aspirações, comunicados de tal modo eloquente e com tamanha espessura de sentimentos que fazem reverberar no leitor tanto sua força de observação da realidade de Moçambique, quanto sua vocação para a invenção. A narrativa traz reflexões relevantes para a compreensão de fenômenos culturais e processos de construção de identidades. Seu experimentalismo linguístico e sua técnica narrativa absorvem elementos da tensão histórico-cultural em que se insere e abre caminhos para compreensão dos pluralismos culturais e das identidades múltiplas.

Mia Couto reitera o compromisso recorrente dos escritores moçambicamos com a práxis política, resistindo ao discurso oficial e trazendo reflexões sobre dinâmicas identitárias, sobretudo no que se traduz como as identidades em movimento. 
Sabemos que toda arte dialoga com seu tempo e representa aspirações, sentimentos e formas de pensamento consoante com o contexto histórico em que se faz. Todavia, é de nosso conhecimento, também, o seu caráter ilimitado temporalmente, o que lhe confere mais o valor estético do que o ideológico, na medida em que traduz desígnios capazes de engendrar mais amplamente a condição de humanidade.

A leitura do conto faz brotar, no imaginário do leitor, uma fisionomia da cultura moçambicana não apenas no momento histórico de produção, mas estende sua percepção para além, à medida que sintetiza possibilidades de convivência para o humano - e isso é atemporal.

\section{CONSIDERAÇÕES FINAIS}

As reflexões trazidas por Mia Couto no conto "A avó, a cidade e o semáforo", bem como os teóricos que contribuíram para problematizar questões que envolvem as inter-relações velho/novo e campo/cidade, configuram um percurso interessante para compreender a noção de identidade.

$\mathrm{Na}$ narrativa em análise, a cidade aparece como espaço praticado pelas relações sociais no mundo moderno a partir das histórias de vida da avó e do neto. A percepção inicial da avó em relação à cidade configura-se cheia de questionamentos e de desconfiança da desordem do espaço urbano para, em seguida, apresentar-se como um espaço de vivências e acolhimentos, o que reverbera que discursos constroem identidades e sujeitos.

O semáforo, com suas cores que evocam fogueiras, traz à avó uma visão positiva do passado, uma recordação de um (velho) espaço já conhecido e que não se perdeu na nova configuração da experiência. Em contrapartida, a referida avó atribui à cidade (ao novo) referências de sociabilidade e referências simbólicas de pertencimento. As identidades, conforme pondera Bauman (2005), estão em constante trânsito, provenientes de diversas fontes. O sujeito se constitui a partir de demarcadores de identidades, como por exemplo, familiar, geracional, étnica, regional, nacional etc. A articulação desses demarcadores conformam a dinamicidade do viver.

Por sua vez, a história, registro dessa multiplicidade, de "raízes móveis", que, ao mesmo tempo em que é fonte de memória, é também fonte de esquecimento, opera no "intervalo", na "rasura", em espécie de escrita dupla. As identidades, conforme Hall (2000), têm relação não com aquilo que nós somos, mas com aquilo no qual nos tornamos. É imensamente mais relevante "quem nós podemos nos tornar" do que quem somos nós e de onde viemos. Dito de outro modo, "não é retorno às raízes, mas negociação com nossas rotas".

Mia Couto não busca o retorno à tradição, mas aposta na ressignificação dessas experiências, acreditando que, no trânsito multidirecional dos elementos identitários, pode-se construir a moçambicanidade, ou seja, a transcriação desses imaginários plurais guarda a senha do porvir. 
A literatura, como uma das linguagens do imaginário, opera com a lição de que fala Hoggart, permitindo-nos reflexões e trânsitos interdisciplinares que nos fazem reorganizar, de outra maneira, a compreensão das experiências e permite enriquecer visões de mundo ao favorecer leituras múltiplas de realidades complexas muitas vezes inacessíveis. Os recentes estudos críticos de literatura africana de expressão portuguesa, lidos à luz dos Estudos Culturais e dos Estudos Pós-coloniais, têm sinalizado caminhos para a compreensão do outro, de modo a propiciar a civilização de nossas relações a partir de uma consciência ética sobre as culturas e as identidades.

Recebido para publicação em 28/02/2017

Aprovado em 14/06/2017

\section{NOTAS}

1 Professora do Mestrado Interdisciplinar em Ciências Humanas e do Curso de Comunicação da Universidade de Santo Amaro - UNISA, SP. Doutora em Comunicação e Informação pela Universidade Federal do Rio Grande do Sul - UFRGS. E-mail: lourde_silva@ hotmail.com

${ }^{2}$ Professora do Mestrado Interdisciplinar em Ciências Humanas da Universidade de Santo Amaro - UNISA, SP. Doutora em Estudos Comparados de Literaturas de Língua Portuguesa pela Universidade de São Paulo, e-mail:mbaseio@uol.com.br.

\section{REFERÊNCIAS BIBLIOGRÁFICAS}

BASEIO, Maria Auxiliadora Fontana. Entre a magia da voz e a artesania da letra: o sagrado em Manoel de Barros e Mia Couto. 274f. 2007. Tese (Doutorado em Letras) Faculdade de Filosofia, Letras e Ciências Humanas, Universidade de São Paulo, 2007.

BOSI, Ecléa. Memória e Sociedade. 3.ed. São Paulo: Companhia das Letras, 1994.

BOURDIEU, Pierre. O poder simbólico. Rio de Janeiro: Bertrand Brasil, 2006.

CALVINO, Ítalo. As cidades invisíveis. Rio de Janeiro: Companhia das Letras, 1990.

CANCLINI, Néstor García. Diferentes, desiguais e desconectados: mapas da interculturalidade. Rio de Janeiro: Ed. UFRJ, 2005.

CANDIDO, Antonio. Formação da literatura brasileira. 8. ed. Belo Horizonte: Itatiaia,1997, v. 1.

CASTELLS, Manuel. A sociedade em rede. São Paulo: Paz e Terra, 1999.

CERTEAU, Michel de. A invenção do cotidiano: artes de fazer. Petrópolis: Vozes, 1998.

CEVASCO, Maria Eliza. Dez Lições Sobre os Estudos Culturais. São Paulo: Boitempo Editorial, 2003. 
COUTO, Mia. A varanda do frangipani. 7. ed. Lisboa: Editorial Caminho, 2003.

1998.

. Estórias Abensonhadas. 2. ed. Lisboa: Editorial Caminho,

. O fio das miçangas. 4. ed. Lisboa: Editorial Caminho, 2004.

. O último voo do flamingo. São Paulo: Companhia das Letras, 2005.

minho, 2005 .

Pensatempos: textos de opinião. 2. ed. Lisboa: Editorial Ca-

. Raiz de Orvalho e outros poemas. Lisboa: Editorial Caminho, 1999.

Um rio chamado tempo, uma casa chamada terra. São Paulo: Companhia das Letras, 2003.

HALL, Stuart. A centralidade da cultura: notas sobre as revoluções culturais do nosso tempo. Educação \& Realidade. v. 22, n.2, p.15-46, jul./ dez de 1997.

Quem precisa da identidade? In: SILVA, Tomaz Tadeu (org. e trad.). Identidade e diferença: a perspectiva dos estudos culturais. Petrópolis: Vozes, 2000. p. 103-133.

MATOS, Gyslaine A. A palavra do contador de histórias. São Paulo: Martins Fontes, 2005.

MOISES, Massaud. Literatura: mundo e forma. São Paulo: Cultrix, Edusp, 1982.

MORIN, E. Cabeça bem-feita. Tradução Eloá Jacobina. 20.ed. Rio de Janeiro: Bertrand Brasil, 2012.

PADILHA, Laura Cavalcante. Entre voz e letra: o lugar da ancestralidade na ficção angolana do século XX. Rio de Janeiro: EDUFF, 1995.

SILVA, Lourdes Ana Pereira. Elementos de construção de identidades na telenovela brasileira (2000-2009). In: XI Congresso de Comunicação na Região Sul, 2010, Novo Hamburgo. Anais do XI Congresso de Comunicação na Região Sul, 2010.

SILVA, Tomaz Tadeu da (org.). A produção social da identidade e da diferença. In: Identidade e diferença: a perspectiva dos estudos culturais. Petrópolis, Rio de Janeiro: Ed. Vozes, 2000.

WILLIAMS, Raymond. O campo e a cidade: na história e na literatura. São Paulo: Companhia das Letras, 2011.

. Cultura. Tradução de Lólio Lourenço de Oliveira. Rio de Janeiro: Paz e Terra, 1992. 